\title{
Continuous Insulin infusion therapy for acute stress hyperglycaemia secondary to asthma exacerbation in a paediatric emergency setting
}

\author{
Harsha Hanumanthaiah', Arundoss Gangadharan' and Sze May $\mathrm{Ng}^{1 *}$ \\ *Correspondence: May.ng@nhs.net \\ 'Department of Paediatrics, Southport and Ormskirk NHS Trust, Wigan Road, Ormskirk L39 2AZ, United Kingdom.
}

\begin{abstract}
Background: Transient mild stress hyperglycaemia is a common clinical finding while severe hyperglycaemia in response to stress is unusual in children. The practice of strict glycaemia control using intravenous insulin therapy remains controversial within paediatric critical care practitioners and considerable disparity exists between physician beliefs and actual practice habits regarding glycaemia control in their critically ill paediatric patients.

Clinical Case: A case of a 5 year old girl without pre-existing diabetes presenting to a paediatric emergency with severe asthma exacerbation and hyperglycaemia is discussed. The patient was commenced on a strict glycaemia control through the use of intravenous intensive insulin therapy. Insulin infusion therapy was safe and effective in the treatment of her persistent severe hyperglycaemia in response to acute stress. No serious adverse side effects of insulin therapy were noted. Conclusion: We recommend that intravenous insulin therapy may be used for initial treatment of severe stress hyperglycaemia in children presenting acutely unwell in an emergency setting.
\end{abstract}

Keywords: Insulin, children, type 1 diabetes, basal bolus.

\section{Introduction}

Hyperglycaemia is thought to be an adaptive response to stress and is recognized to be associated with an adverse outcome. Although mild stress hyperglycaemia in paediatric illness is common, severe hyperglycaemic responses ( $\geq 25 \mathrm{mmol} / \mathrm{L}$ ) to stress are unusual in children. The role of intravenous insulin infusion therapy in the treatment of stress related hyperglycaemia in hospitalised adults have shown improved outcomes, however, its use in children remains a controversy.

We report a case of acute severe stress hyperglycaemia in 5 year old girl without pre-existing diabetes presenting with severe asthma exacerbation in an emergency setting. We describe the success of insulin therapy in controlling her high blood sugars with ketonuria.

\section{Clinical report}

A 5 year old girl presented acutely unwell to the paediatric accident and emergency with severe exacerbation of asthma. She had a one day history of shortness of breath, abdominal pain and vomiting. On admission her weight was $19.0 \mathrm{~kg}$, height $113 \mathrm{~cm}$, body mass index 15 and there were no signs of insulin resistance such as acanthosis nigricans. Her laboratory investigations on admission are shown in Table 1. She had a peak concentration of true blood glucose in plasma of $23 \mathrm{mmol} / \mathrm{L}$ and a blood ketone level of $4.0 \mathrm{mmol} / \mathrm{L}$ on admission. She was started on the acute asthma management protocol requiring intravenous aminophylline, hydrocortisone and hourly nebulised bronchodilators. Her pH on admission was 7.28 with compensated metabolic acidosis and a base excess of -8.8. She was commenced on a normal saline infusion and intravenous insulin (Actrapid) therapy according to the British Society of Paediatric Endocrinology and Diabetes 2009 [1] diabetes ketoacidosis protocol at an initial rate of 0.1 units/kilogram/hour. Her blood glucose levels responded from $23 \mathrm{mmol} / \mathrm{L}$ to $5 \mathrm{mmol} / \mathrm{L}$ within 8 hours from commencing the insulin infusion. When her $\mathrm{pH}$ was greater than 7.3, the insulin infusion was decreased to 0.05 units $/ \mathrm{kg} /$ hour and eventually her blood sugars remained stable between $4-8 \mathrm{mmol} / \mathrm{L}$ after 16 hours on the intravenous insulin regimen.

She was investigated for insulin deficiency in view of the significant severe hyperglycaemia. There was no family history of Type 1 or 2 diabetes or autoimmune disorders. C-peptide levels were $1346 \mathrm{pmol} / \mathrm{L}$, plasma insulin $41.2 \mathrm{mU} / \mathrm{L}$ and her anti-insulin and anti-GAD antibodies were negative. Random and fasting blood sugar monitoring from day 2 was normalised. She had an oral glucose tolerance test 6 months after the incident 
Table 1. Laboratory investigations on admission

\begin{tabular}{llll}
\hline & & Unit & Range \\
\hline Sodium & 133 & $\mathrm{mmol} / \mathrm{L}$ & $(133-146)$ \\
Potassium & 3.8 & $\mathrm{mmol} / \mathrm{L}$ & $(3.5-5.2)$ \\
Urea & 4.2 & $\mathrm{mmol} / \mathrm{L}$ & $(2.3-7.0)$ \\
Creatinine & 46 & $\mathrm{mmol} / \mathrm{L}$ & $(0-110)$ \\
Plasma Glucose & 23.0 & $\mathrm{mmol} / \mathrm{L}$ & $(4.0-11.0)$ \\
Haemoglobin & 12.9 & $\mathrm{~g} / \mathrm{L}$ & $(11.5-13.5)$ \\
White cell count & 24.1 & $\times 10^{9} / \mathrm{L}$ & $(5 .-17.0)$ \\
Platelets & 450 & $\times 10^{9} / \mathrm{L}$ & $(140-440)$ \\
Haematocrit & 0.38 & - & $(0.34-0.40)$ \\
Neutrophils & 22.0 & $\times 10^{9} / \mathrm{L}$ & $(1.5-8.5)$ \\
Lymphocyte & 1.5 & $\times 10^{9} / \mathrm{L}$ & $(1.5-9.5)$ \\
Monocyte & 0.8 & $\times 10^{9} / \mathrm{L}$ & $(0.2-1.2)$ \\
Eosinophil & 0.2 & $\mathrm{x} 10^{9} / \mathrm{L}$ & $(0.0-0.8)$ \\
\hline
\end{tabular}

which was reported to be normal (fasting blood glucose was $5.7 \mathrm{mmol} / \mathrm{L}$ and 2 hour blood glucose was $10 \mathrm{mmol} / \mathrm{L}$ ). She has been discharged from the outpatient clinic after a period of 18 months follow up.

\section{Discussion}

The underlying causes of hospital-related hyperglycaemia and mechanisms explaining the deleterious effects of hyperglycaemia and improved outcomes with insulin intervention are discussed. Current guidelines from various professional organisations differ in the recommendation of treatment of inpatient hyperglycaemia, while exact glycaemic targets and identification of which patient subsets will receive greatest benefit from glucose lowering remain an area of ongoing research.

Importantly, the distinction between hyperglycaemia as a prediabetic state and that as a physiological response to stress during acute illness should be determined as hyperglycaemia during an acute illness may represent the earliest clinical sign of impaired beta cell function.

Shehadeh et al., found that episodes of hyperglycaemia during severe illness without additional risk factors such as immunologic markers (insulin autoantibodies and islet cell autoantibodies) and a positive intravenous glucose tolerance test are a minimal risk factor for future development of Type 1 diabetes mellitus [2]. In all 36 children followed up for a mean of 3.2 years, none of the patients developed diabetes including those with positive immunological markers. In a separate study, in 63 children with transient hyperglycaemia, insulin-dependent diabetes mellitus developed within 18 months of identification in $32 \%$ of these children and presence of islet cell antibodies and competitive insulin autoantibodies each had a $100 \%$ positive predictive value for IDDM [3]. Bhisitkul et al., showed that children who develop transient stress hyperglycaemia do not have an increased prevalence of immunologic or genetic markers of insulin-dependent diabetes mellitus and thus do not appear to be at an increased risk for development of insulin-dependent diabetes mellitus [4]. None of these studies reported severe hyperglycaemia requiring transient insulin therapy.

Hyperglycaemia is common in critically ill patients and is associated with increased morbidity and mortality. Hyperglycaemia in can cause osmotic diuresis with resultant loss of water and electrolytes leading to dehydration. Hyperglycaemia is also associated with intracranial haemorrhage and death [5]. Correction of severe hyperglycaemia during illness has been shown to decrease morbidity and mortality however, establishing evidence-based guidelines has been challenging. The practice of strict glycaemia control using intravenous insulin therapy remains controversial within paediatric critical care practitioners due to documented increase in the incidence of hypoglycaemia and considerable disparity exists between physician beliefs and actual practice habits regarding glycaemia control in their critically ill paediatric patients [6].

In this case report, continuous insulin infusion was a relatively safe and effective in the treatment of acute and severe hyperglycaemia in response to acute stress from an asthma exacerbation. Insulin therapy also avoided the complication of a catabolic state. No serious adverse side effects of insulin therapy were noted throughout the patient's care. The hyperglycaemic response was not thought to be a prediabetic state as the patient did not have significant family history for diabetes and all immunological markers were absent. Long term follow up revealed no adverse outcome.

We recommend that intravenous insulin therapy may be used for the initial treatment of severe stress hyperglycaemia in children presenting acutely unwell in an emergency setting. The authors believe that in such an uncommon case, it is important that management with intravenous insulin infusion be promptly instituted. Children may present with acute severe hyperglycemia in response to severe stress in an emergency setting and in the absence of any risk factors such as immunologic or genetic markers of insulindependent diabetes mellitus, they are not at an increased risk for development of insulin-dependent diabetes.

\section{Competing interests}

The authors' declare that they have no competing interests.

\section{Authors' contribution}

All authors have contributed significantly and are in agreement with the content of the manuscript.

\section{Publication history}

Recieved: 14-Nov-2012 Revised: 03-Dec-2012

Accepted: 05-Dec-2012 Published: 07-Dec-2012 


\section{References}

1. BSPED Recommended DKA Guidelines 2009. In. 2009 ed: PDF

2. Shehadeh N, On A, Kessel I, Perlman R, Even L, Naveh T, Soloveichik L, Etzioni $A$. Stress hyperglycemia and the risk for the development of type 1 diabetes. J Pediatr Endocrinol Metab. 1997; 10:283-6. | Article | PubMed

3. Herskowitz-Dumont R, Wolfsdorf JI, Jackson RA, Eisenbarth GS.

Distinction between transient hyperglycemia and early insulindependent diabetes mellitus in childhood: a prospective study of incidence and prognostic factors. J Pediatr. 1993; 123:347-54. | Article I PubMed

4. Bhisitkul DM, Vinik Al, Morrow AL, She JX, Shults J, Powers AC, Maclaren NK. Prediabetic markers in children with stress hyperglycemia. Arch Pediatr Adolesc Med. 1996; 150:936-41. | Article I PubMed

5. Ulate KP, Raj S, Rotta AT. Critical illness hyperglycemia in pediatric cardiac surgery. J Diabetes Sci Technol. 2012; 6:29-36. | Article | PubMed

6. Preissig CM, Rigby MR. A disparity between physician attitudes and practice regarding hyperglycemia in pediatric intensive care units in the United States: a survey on actual practice habits. Crit Care. 2010; 14:R11. | Article | PubMed Abstract | PubMed Full Text 